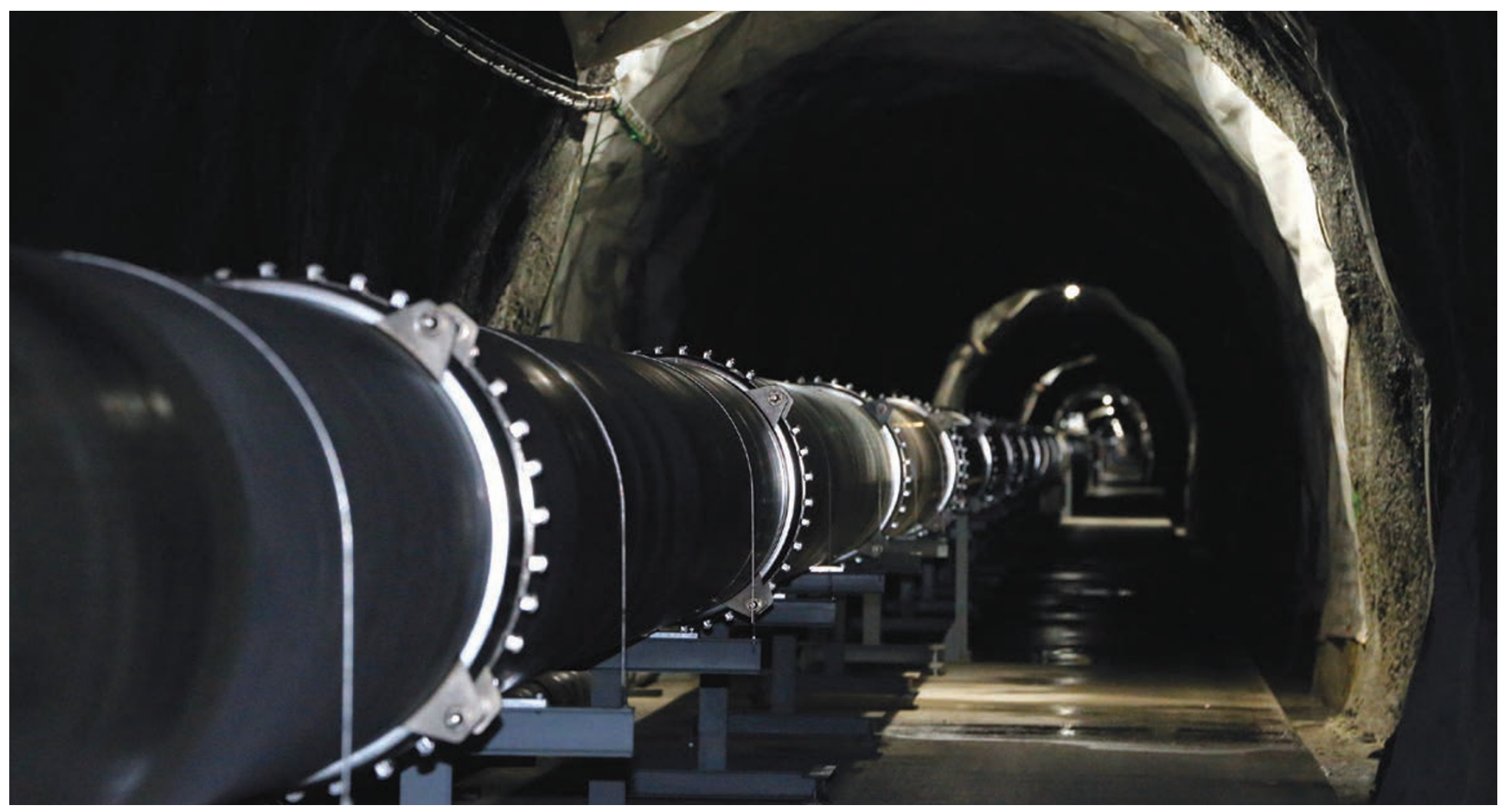

The Kamioka Gravitational Wave Detector (KAGRA), housed in a giant tunnel, is a project of University of Tokyo's Institute for Cosmic Ray Research.

\title{
EYE ON THE PRIZE, BUT GRASP LOOSENS
}

\section{In most of the past 15 years, Japanese scientists have been named Nobel Laureates for work in chemistry and physics, but illustrious awards may be harder to come by in the next era.}

\section{BY TIM HORNYAK}

$\mathrm{M}$ odern Japanese research is a tale of two eras. While the nation's scientists have been recognized with Nobel Prizes for work in fields such as chemistry and physics in the majority of the last 15 years, some observers predict that such awards will be more elusive for the next 15 .

University of Tokyo physicist, Takaaki Kajita, the most recent laureate, was honoured, along with Canada's Arthur B. McDonald, in 2015 for showing that neutrinos can oscillate, demonstrating that they also have mass - a revelation that defied the standard model of particle physics.

The achievement solidified the University of Tokyo's dominant position over other Japanese research centres. It holds the country's top spot in 2015 in the Nature Index, a database of the contributions scientists have made to 68 high-quality science journals. The index tallies the annual number of scholarly papers affiliated with a particular institution, the relative contribution of each author to a particular study, known as the fractional count, and the weighted fractional count (WFC), which adjusts for the relative abundance of papers in astronomy and astrophysics. Between 2014 and 2015, the University of Tokyo's WFC rose $6 \%$, the largest increase of any institution in the Nature Index top 10.

Perhaps unsurprisingly, seven of the top 10 Japanese institutions in the index form the state-backed National Seven Universities, a group analogous with the Ivy League schools in the United States.

The top 10 carry out research supported by a combination of government funding and collaborations with the private sector, though the latter has been taking on an increasingly significant role.

Despite the country's impressive Nobel Prize cabinet, by other measures of success there may be cause for concern. Between 2012 and 2015 the output of high-quality science counted in the Nature Index declined for eight out of Japan's "The number top 10 institutions. of scientific articles in Japan normalized by population or GDP is less than half that of many OECD countries." analysis by Nagayasu Toyoda, president of Suzuka University of Medical Sciences.

"The number of scientific articles in Japan normalized by population or GDP is less than half that of many OECD countries," says Toyoda, who anticipates fewer Nobel Prizes for Japan.

"The main reason for the decline in research activity at Japanese universities is budget cuts to basic subsidies to national universities by about $1 \%$ or more per year during the past 10 years and beyond."

This will have an impact on Japanese science, as top researchers have historically been able to leverage their reputation to try to break new ground. For instance, Kajita has been working toward the direct detection of a gravitational wave. Predicted by Einstein's theory of relativity, gravitational waves can distort spacetime in minute quantities - equivalent to the diameter of a hydrogen atom for the distance between the Earth and the Sun.

The recent detection of gravitational waves could be the beginning of a new kind of astronomy. Kajita is supervising a project to build a 3-km laser interferometer. "The beginning of the universe is an ultimate goal, but for the moment our hope is to observe the formation of black holes." 


\section{TOP OF THE NATION}

Japan's top 10 overall performers in the Nature Index in 2015 include the National Seven Universities,

government funded research institutions and

up-and-coming research universities.

\section{UNIVERSITY OF TOKYO} 2015 WFC: 486

2 KYOTO UNIVERSITY

22015 WFC: 270

3 OSAKA UNIVERSITY

3 2015 WFC: 194

4 TOHOKU UNIVERSITY

42015 WFC: 176

5 RIKEN

52015 WFC: 137

See RIKEN profile

6 NAGOYA UNIVERSITY

62015 WFC: 127

7 TOKYO INSTITUTE OF TECHNOLOGY

2015 WFC: 120

8 HOKKAIDO UNIVERSITY

8 2015 WFC: 103

9 KYUSHU UNIVERSITY

2015 WFC: 85

10 NATIONAL INSTITUTE FOR MATERIAL SCIENCE 2015 WFC: 82

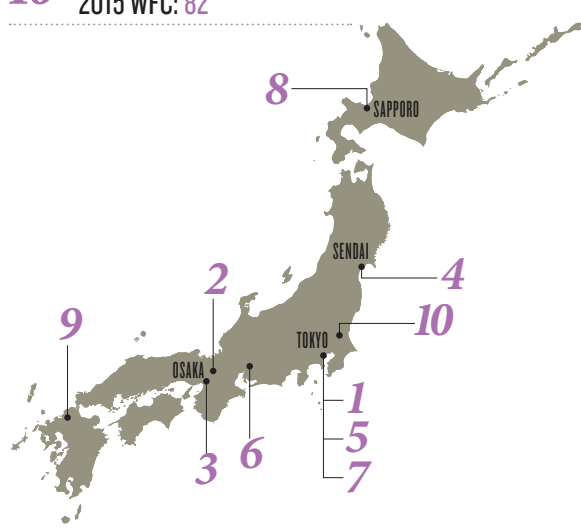

WFC output from 2012 to 2015 for Japan's top 5 universities in the Nature Index.
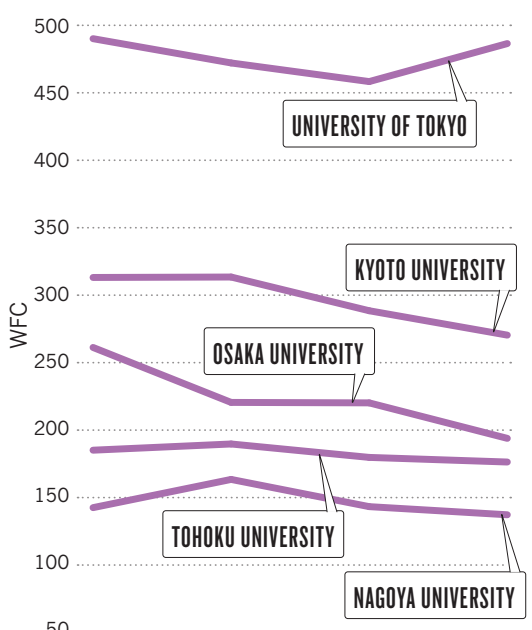

50 research grants and collaborative research with industry for about one-third of its budget. Of its 23.5 billion Grants-in-Aid for Scientific Research from the state-backed Japan Society for the

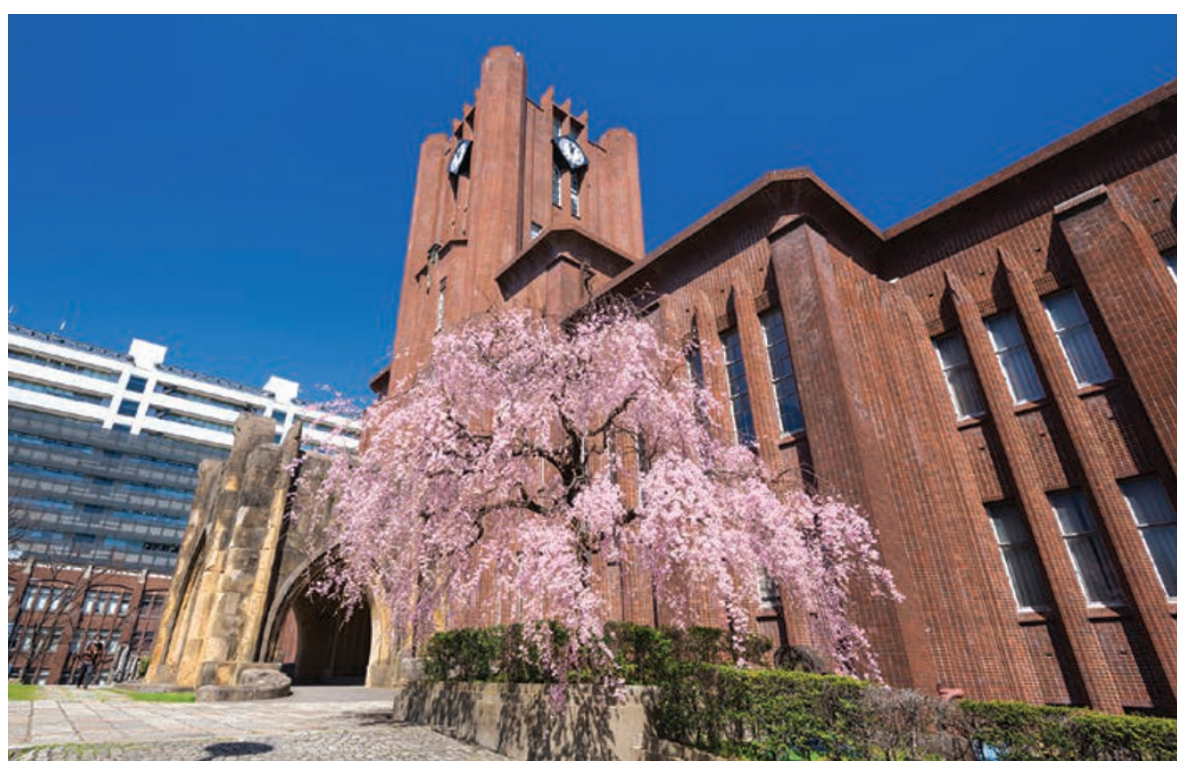

The University of Tokyo has been a stronghold of excellence in Japanese science since its establishment.

\section{UNIVERSITY OF TOKYO}

2015 WFC: 4862015 AC: 1,377

\section{NATURE INDEX ACADEMIC RANKING: 3}

Measuring the performance of University of Tokyo in a global context over time. The line graph below compares University of Tokyo (purple) with peers with a similar WFC output in the Nature Index 2015. The donut shows WFC output by subject area in 2015.
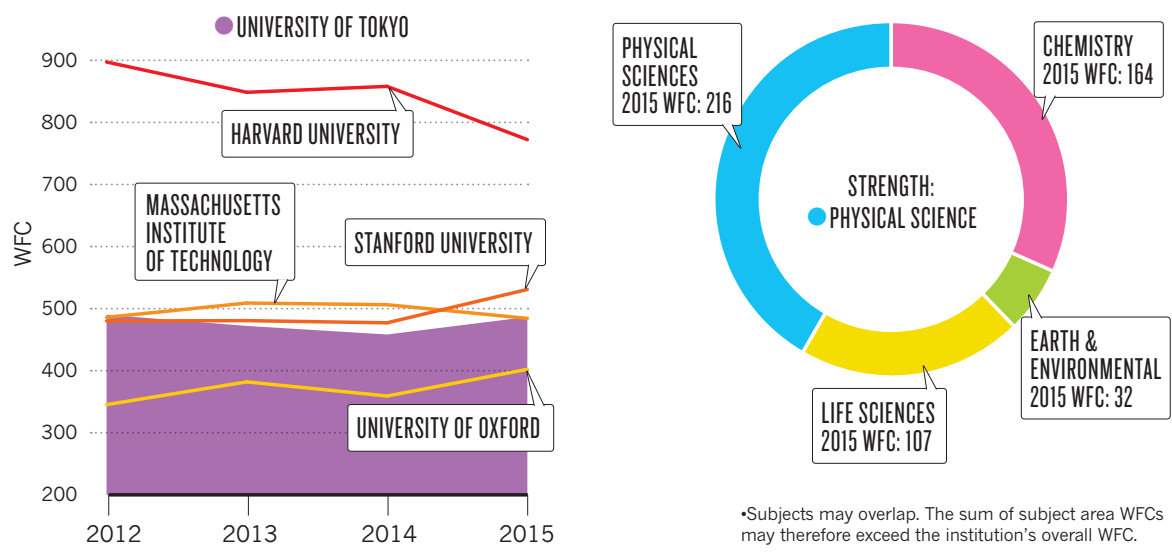

-Subjects may overlap. The sum of subject area WFCs may therefore exceed the institution's overall WFC.

Founded in the decade after Japan's emergence from feudalism in 1868, the University of Tokyo has long presided over the ranks of Japanese centres of learning. Today, it comprises 10 faculties, 15 graduate schools, 13 research centers and facilities located throughout Japan. Among its scholars are eight Nobel Prize winners and one Fields Medal winner. To maintain its research output, the university relies on
"Members of the University of Tolkyo are active across the of human endeavour." full spectrum
Promotion of Science (JSPS), more than half is used to support fundamental research, and $16 \%$ goes to support young researchers.

"Research today is ever more specialized and increasingly requires the efforts of teams working across disciplinary boundaries," says Kazuo Hotate, executive vice president for research at the university. "One of our great strengths is that members of the University of Tokyo are active across the full spectrum of human endeavour, providing immense opportunity for interdisciplinary collaboration both within the university and with our partners across Japan and the world." 


\section{KYOTO UNIVERSITY}

2015 WFC: 270 2015 AC: 715

2015 NATURE INDEX ACADEMIC RANKING: 14

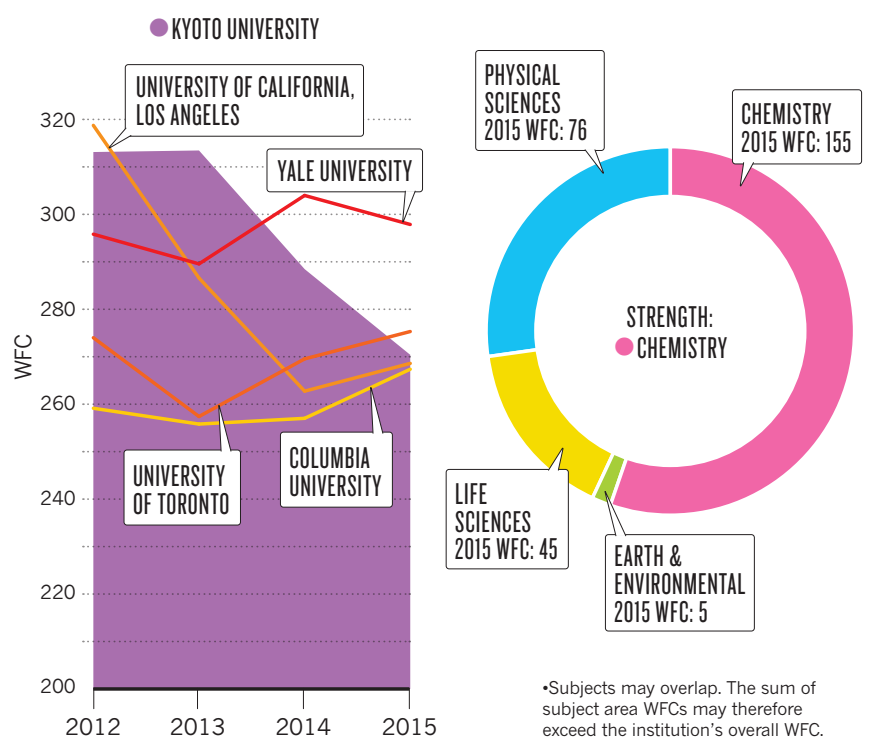

Like the University of Tokyo, Kyoto University has produced a number of outstanding researchers since its establishment in the late 19th century - nine have won a Nobel Prize, including Shinya Yamanaka in 2012 for discovering that mature cells can be reprogrammed into so-called induced pluripotent (iPS) cells (described in the journal Cell).

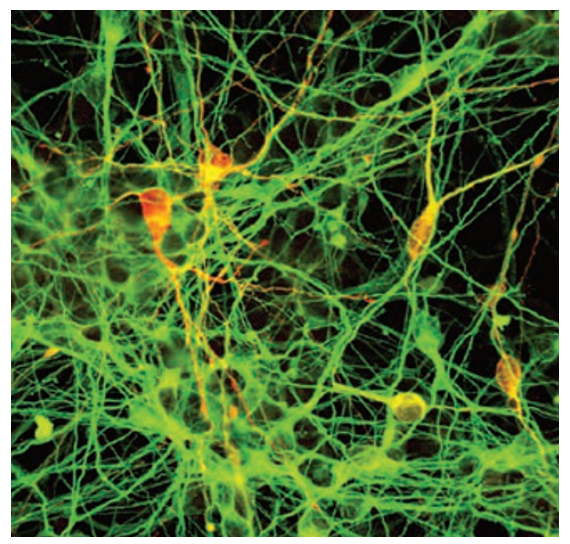

Neurons derived from iPS cells, whose discovery earned Shinya Yamanaka a Nobel Prize in 2012.

Yamanaka wrote about streamlining iPS cell research in Nature in 2009. Today, Kyoto has 14 research institutes including the Center for iPS Research and Application (CiRA), where Yamanaka is director. Following partial privatization in 2004, along with all other national universities, government block funding has been decreasing. Kyoto University has responded by increasing joint projects

$\begin{array}{ll}\text { "KUhas } & \text { with corporate } \\ \text { tended to } & \text { partners as well } \\ \text { attract } & \text { as taking on } \\ \text { the best } & \text { corporate-spon- } \\ \text { minds in } & \text { sored research, } \\ \text { Japanese } & \text { which now } \\ \text { academia." } & \text { accounts for }\end{array}$

about $42 \%$ of the research budget. An example of the embrace of industry is T-CiRA, a 10-year collaboration between CiRA and Takeda Pharmaceutical Company, Japan's largest drug maker, to develop clinical applications of iPS cells. "This system of innovation is seen as being in tune with the city of Kyoto, where tradition combines with creativity to result in an environment fostering venture businesses," says the university spokesman, David Hajime Kornhauser. "KU has tended to attract the best minds in Japanese academia: those who are seeking a place to pursue their ideas freely and express their creative spirit to the utmost".

\section{OSAKA UNIVERSITY}

2015 WFC: 1932015 AC: 532

\section{NATURE INDEX ACADEMIC RANKING: 34}

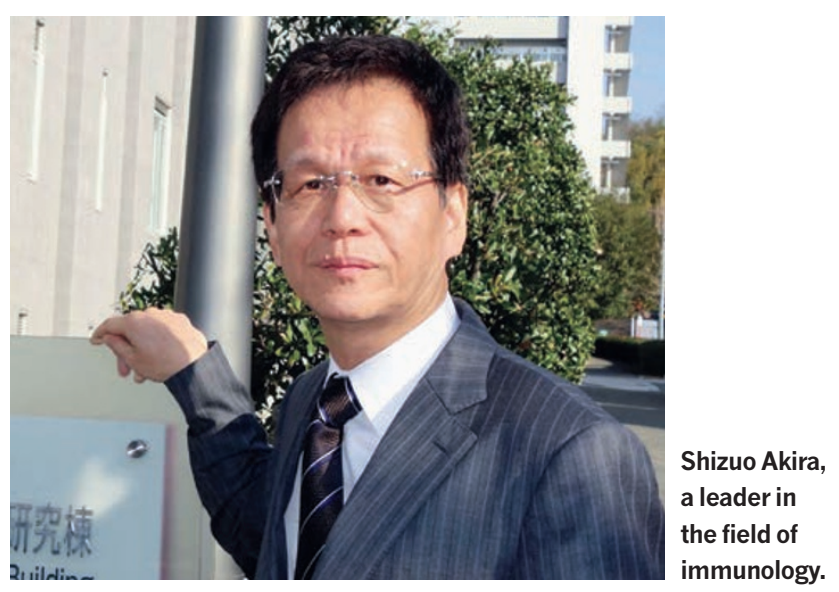

Osaka University is known for its immunology discoveries. It was at this institution that the emeritus professor, Tadamitsu Kishimoto, identified the immune protein interleukin- 6 in the 1980s. Today the university is trying to clear a path to the next breakthroughs in the field through the Osaka University Immunology Frontier Research Center (IFReC). Opened in 2007 as one of the Japanese government's "globally visible" World Premier Institute Research Institutes, IFReC aims to broaden the scope of immunology research to include study of cells in the body and come up with solutions to immune diseases including vaccine development. The staff of more than 20 researchers in

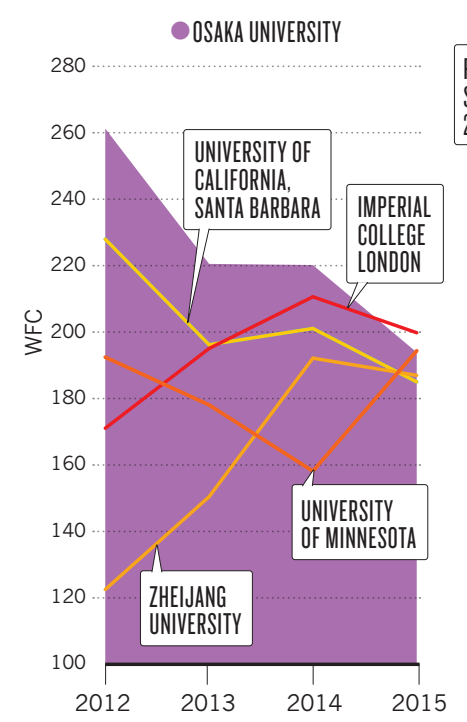

immunology, bioinformatics and imaging have elucidated links between the immune system and metabolic syndromes including lipolysis and gout, described in

$$
\text { 2013. Direc- }
$$

"In 2016,I tor, Shizuo expectrobust Akira, said achievements the centre in thesefields." had published more than 1,000 papers on a wide variety of immunology fields, almost $10 \%$ of them in high-impact journals. Akira, who studied in Kishimoto’s lab, said: "Our laboratory is actively involved in the determination of new subsets of macrophage and regulation of post RNA transcription. In 2016, I expect robust achievements in these fields." 


\section{TOHOKU UNIVERSITY}

\section{WFC: 1762015 AC: 429}

\section{NATURE INDEX ACADEMIC RANKING: 38}

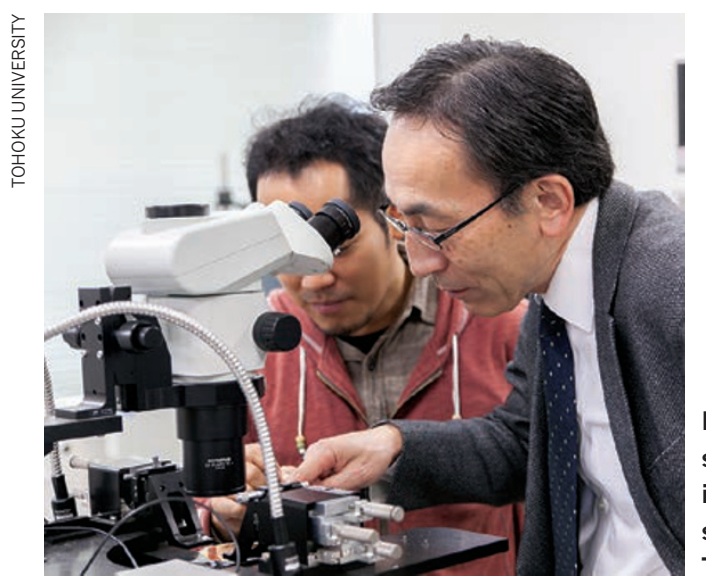

Hideo Ohno uses a stereomicroscope in the study of spintronics at Tohoku University.
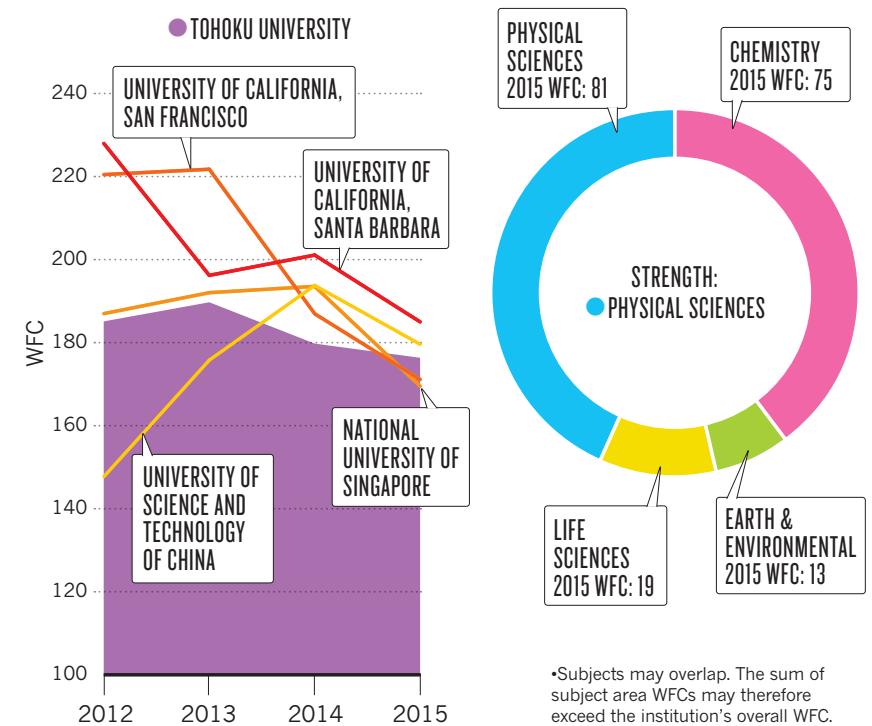

Hideo Ohno spent 10 years researching semiconductors in his hometown of Sapporo before he became curious about the possibilities of combining magnets with these indispensable devices of the information age. In 1994

he began to explore this in earnest, when he joined the faculty of Tohoku University's Department of Electronic Engineering. Ohno is now the director of the Center for Spintronics Integrated Systems. "Spintronics is a broad science and engineering field, in which we utilize the 'spin' (a magnetic property) of the electron," says Ohno. In a 2015 Nature Physics paper, Ohno and collaborators described the so-called 'creep' slow motion of domain

walls in ferromagnets. As a practical application, spintronics could transform household appliances and factory equipment into 'smart' devices that collect and exchange data via the internet. It has been used to make highperformance nonvolatile memory storage, which doesn't require energy to retain information.

This helps countless processors and controllers stand by without power, an essential quality for the 'Internet of things'. Joining Tohoku gave Ohno the opportunity to lead a group, and access the best equipment to develop new materials and study spintronics. So what does Ohno have in store for 2016? "This is top secret," he says.

\section{NAGOYA UNIVERSITY}

2015 WFC: 1262015 AC: 433

\section{NATURE INDEX ACADEMIC RANKING: 60}
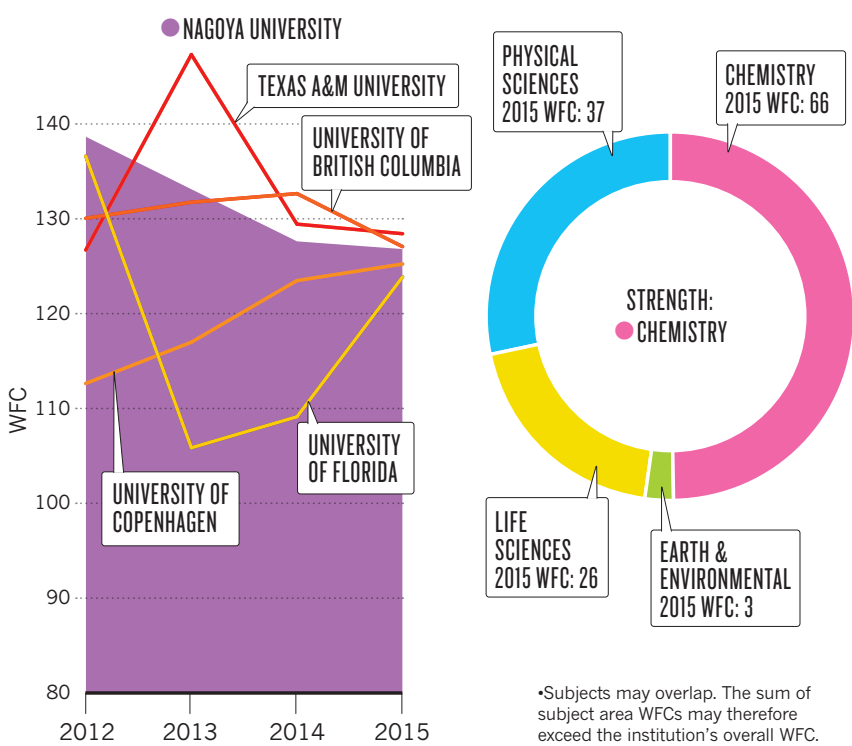

Like every kid growing up in Hamamatsu City, Hiroshi Amano knew about hometown legend Kenjiro Takayanagi, a high-school teacher and inventor who created the first fully electronic TV screen in 1926. But Amano also dreamed of exceeding his achievement. The spark came when he studied engineering at Nagoya University and became interested in PCs. He wondered whether compact light-emitting diodes (LEDs) could replace the bulky cathode-ray tubes that were used in Takayanagi's early TVs as

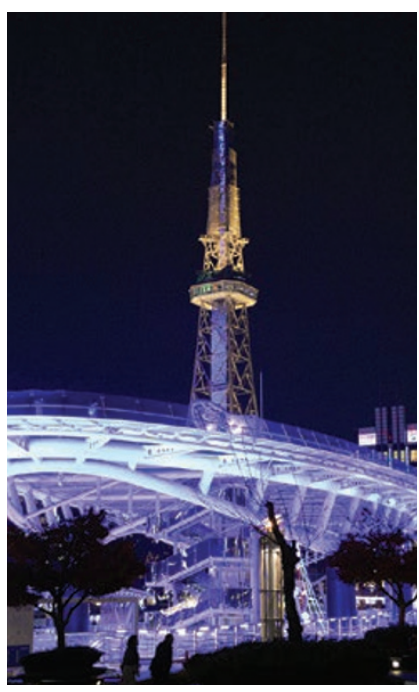

Blue LEDs illuminate the Nagoya TV tower to celebrate their launch. well as PC displays. "I believed that if I could develop a blue LED, I would change the world," Amano says. "Of course, I was a fledgling student and I knew nothing about the difficulty of the subject." His boldness paid off. In 1985, Amano produced the world's first highluminance blue LED, along with his supervisor, Isamu Akasaki, who focused on gallium nitride as a promising material. His research has also appeared in Nature Materials. The achievement won them the 2014 Nobel Prize in Physics, shared with Shuji Nakamura. Today blue LEDs are used in everything from mobile phone backlights to energy-efficient traffic signals and lights for plant cultivation.

Nagoya is a national university that traces its roots back to a medical school founded in 1871 in a samurai court. These days the university's strengths are chemistry and physical sciences.

With a relatively light teaching load compared to faculty at private universities, Amano says he can concentrate on his research which is now focused on the potential of deep ultraviolet (DUV) LEDs for sterilization."We could provide safe water for 2.4 billion people without safe sanitation and 663 million people who cannot access safe drinking water," he says. 